\title{
Lateral Nasal Artery Perforator Flaps: Anatomic Study and Clinical Applications
}

\author{
Giuseppe AG Lombardo, Serena Tamburino, Luciano Tracia, Maria Stella Tarico, \\ Rosario Emanuele Perrotta \\ Department of Plastic and Reconstructive Surgery, Cannizzaro Hospital, Catania, Italy
}

Background Previous studies have investigated facial artery perforators, but have reported inconsistent results regarding lateral nasal artery (LNA) perforators. Although several authors have described the use of LNA perforators for ala nasi and nasal sidewall reconstruction, the literature contains little information regarding the cadaveric dissection of LNA perforators, and most previously published studies have focused on facial artery perforators.

Methods Sixteen hemifaces from eight fresh cadavers were dissected to study the LNA perforators. After the dissection was performed, the total length and diameter of the LNA and its perforators were measured. The quantity and the distribution of the LNA perforators supplying the overlying skin were then assessed. LNA perforator flaps were used for reconstruction in 10 nasal and perinasal defects.

Results The mean total lengths of the LNA and its perforators were $49.37 \mathrm{~mm}$ and $16.06 \mathrm{~mm}$, respectively. The mean diameters of the LNA and its perforators were $2.08 \mathrm{~mm}$ and $0.91 \mathrm{~mm}$, respectively. Based on our findings, we mapped the face to indicate zones with a higher probability of finding perforators. No infection, hematoma, or complete flap necrosis were observed after the procedures.

Conclusions Nasal reconstruction is a challenging procedure, and LNA propeller/N-Y perforator flaps are an excellent reconstructive option in certain cases. Based on our cadaveric study, we were able to identify an area in the upper third of the nasolabial groove with a high density of perforators.

Keywords Perforator flap / Nasolabial fold / Skin neoplasms
Correspondence: Giuseppe AG Lombardo Department of Plastic and Reconstructive Surgery, Cannizzaro Hospital, Via Messina 829, Catania 95129, Italy

Tel: +39-32-9338-7638

Fax: +39-0957264514

E-mail: giuseppelombardouni@gmail. com

No potential conflict of interest relevant to this article was reported.

\section{INTRODUCTION}

Perforator flaps have been used clinically since the last decade of the twentieth century, when Allen and Treece [1] used the deep inferior epigastric artery perforator flap previously described by Koshima and Soeda [2] for breast reconstruction. In 2005, Hofer et al. [3] was the first to apply the perforator technique to the reconstruction of perioral defects, using the facial artery. Since then, a number of studies on the reconstruction of nasal oncologic defects using facial perforators have been published [4-9]. The facial artery perforator-based flap [10] was the first perforator flap for the face. It allows one-stage reconstruction freedom in flap design, while obviating the necessity to adhere to the length-to-width ratio previously considered necessary to 
ensure viability $[8,11]$.

Several anatomic studies have been performed to identify the position and number of the perforators that branch off from the facial artery $[3,12,13]$. While previous studies have mostly focused on the main trunk of the facial artery, in this study we concentrated on the lateral nasal artery (LNA).

The aim of this study was to investigate the perforators of the LNA and their distribution along the course of the vessel. Moreover, the clinical application of the LNA perforator flap is described.

This paper can be considered a guide for approaching this anatomic area with confidence, since preoperative Doppler imaging is not helpful in finding perforators in the LNA.

\section{Anatomy}

Before describing the relevant vascular anatomy, it would be prudent to first highlight some points regarding the anatomy of the facial artery and its branches in the midface. Significant variability exists in the vascular anatomy of this area. For the purposes of this article, we have adopted the nomenclature of more recent authors $[14,15]$, as illustrated in Fig. 1. In describing and naming the lateral nasal and superior labial artery of the facial artery, we have followed the terminology employed by Nakajima et al. [14], which was also used by Loukas et al. [15] in a comprehensive recent anatomic study of the vascular patterns of this area. According to the traditional understanding presented in that study, two major branches arise from the facial artery near the oral commissure: the superior labial artery and the LNA, with the latter terminating as the angular artery (Fig. 1).

\section{METHODS}

\section{Cadaveric study}

Sixteen hemifaces in eight fresh cadavers were dissected under magnifying loupes (Design for Vision 3.5 $\times$ Expanded Field,

Fig. 1. Course of the lateral nasal artery
A fresh cadaveric dissection showing the course of the lateral nasal
artery (LNA, marked in green), from its origin near the facial artery
(FA, marked in red) to where the superior labial artery (SLA, marked
in yellow) splits off from it. The LNA gives off three perforators (P,
marked in light blue). The LNA terminates in the angular artery (AA)
marked in blue.

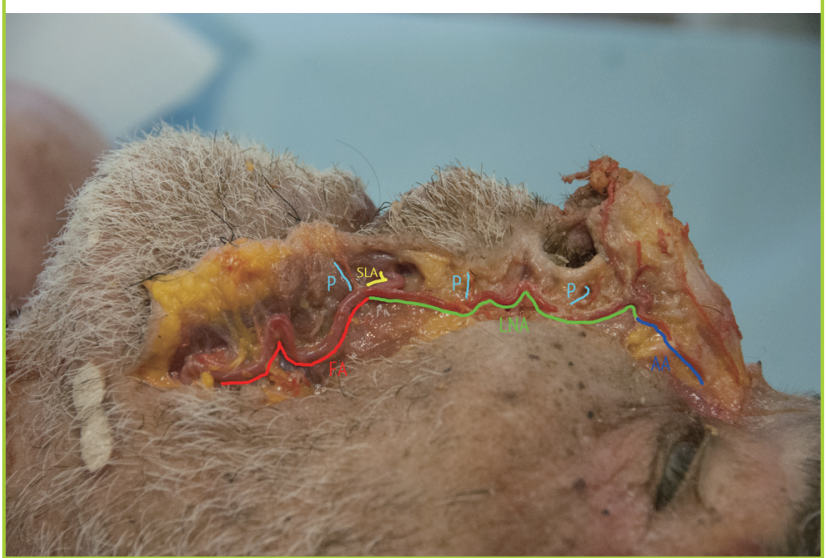

\section{Fig. 2. Facial artery anatomic patterns}

A schematic representation of the three most common distributions of the major branches of the facial artery. (A) In type A, the facial artery bifurcates into the superior labial and lateral nasal arteries. (B) In type B, the facial artery divides into the superior labial and lateral nasal arteries

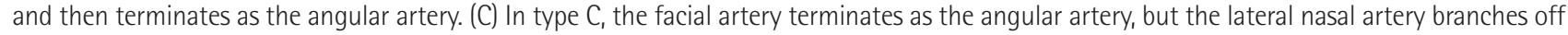
from the superior labial artery [14]. In our anatomic study, type A was the most common, appearing in 10 hemifaces (62.5\%). Type B was found in two hemifaces (12.5\%) and type $\mathrm{C}$ in four hemifaces (25\%).

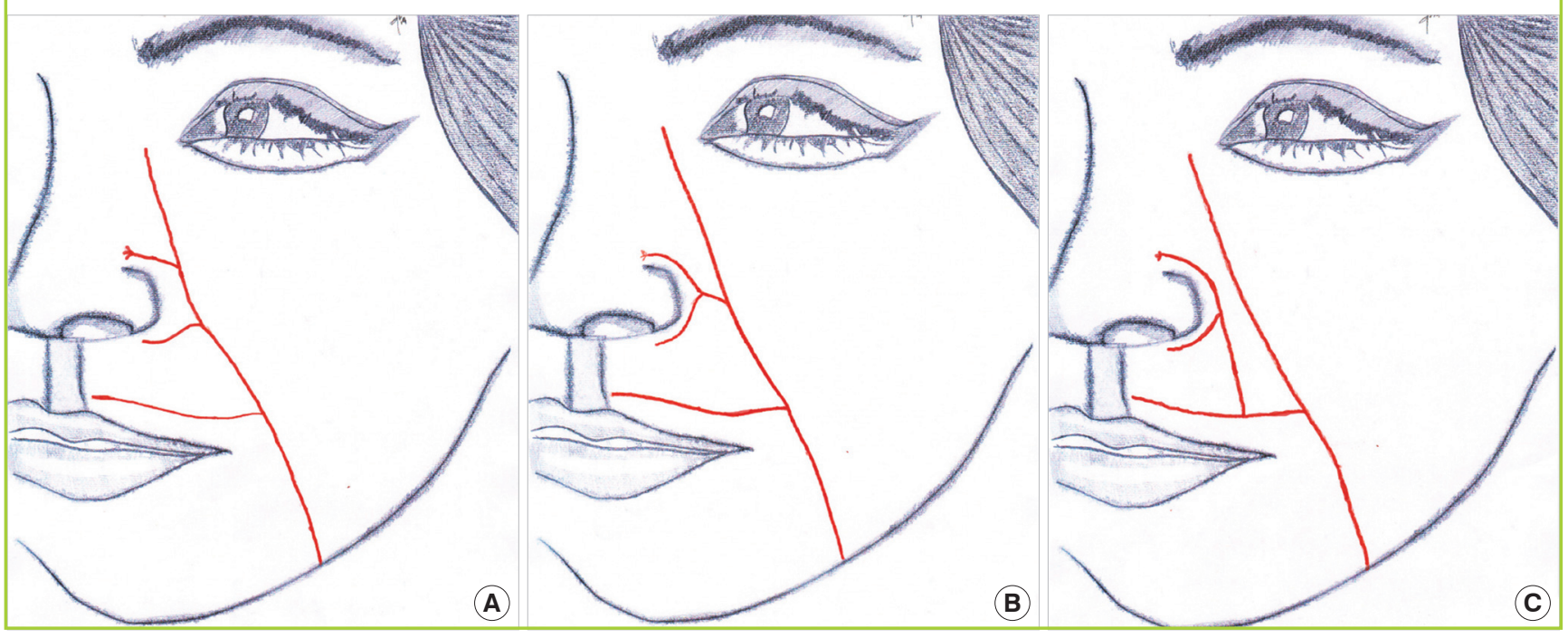


Ronkokoma, NY, USA) to study the LNA perforators.

The LNA was dissected from its origin, where the superior labial artery arises from the facial artery, up until the superior ala nasi margin, where the superior ala nasi artery arises from the LNA and the LNA becomes the angular artery (Fig. 1).

The LNA was dissected in the caudocranial direction in each case to outline its general course according to the classification system modified by Nakajima et al. [14] (Fig. 2).

After the dissection was performed, the total length and diameter of the LNA and its perforators were measured. The quantity and distribution of the LNA perforators supplying the overlying skin were then assessed.

\section{Patients}

LNA perforator flaps were used to reconstruct 10 nasal and perinasal defects between January 2012 and December 2013. The mean age of the patients was 79.9 years (range, 70-87 years). The mean follow-up time was 18 months. In all cases, the defects were secondary after basal cell carcinoma (BCC) excisions.

\section{Surgical technique}

After the tumor was excised, reconstruction was planned, adhering as much as possible to the aesthetic unit principle of nasal reconstruction [16]. The reconstructive stage was approached in a freestyle fashion "from the foliage to the roots," with retrograde dissection of the vessels [17]. Given the proximity of the perfo-

\begin{tabular}{|c|c|c|c|c|}
\hline $\begin{array}{l}\text { Hemifaces/ } \\
\text { (type) }\end{array}$ & $\begin{array}{l}\text { Length } \\
\text { LNA } \\
\text { (cm) }\end{array}$ & $\begin{array}{l}\text { Mean } \\
\text { length LNA } \\
\text { perforators } \\
\quad \text { (cm) }\end{array}$ & $\begin{array}{c}\text { Diameter } \\
\text { LNA } \\
\text { (mm) }\end{array}$ & $\begin{array}{l}\text { Mean } \\
\text { diameter LNA } \\
\text { perforators } \\
(\mathrm{mm})\end{array}$ \\
\hline $1 \mathrm{a}(\mathrm{C})$ & 5.0 & 1.30 & 2.2 & 0.65 \\
\hline $1 b(A)$ & 5.2 & 1.45 & 2.2 & 1.00 \\
\hline $2 \mathrm{a}(\mathrm{A})$ & 4.4 & 1.75 & 2.0 & 0.9 \\
\hline $2 b(A)$ & 4.5 & 1.80 & 2.1 & 0.9 \\
\hline $3 a(A)$ & 4.5 & 1.45 & 2.0 & 1.10 \\
\hline $3 b(C)$ & 4.4 & 1.50 & 1.9 & 0.90 \\
\hline $4 a(B)$ & 4.0 & 1.35 & 2.0 & 0.75 \\
\hline $4 b(A)$ & 4.5 & 1.75 & 1.8 & 1.15 \\
\hline $5 a(A)$ & 4.9 & 1.50 & 2.5 & 1.25 \\
\hline $5 b(C)$ & 4.8 & 1.65 & 1.7 & 0.70 \\
\hline $6 a(B)$ & 6.0 & 1.75 & 2.5 & 0.90 \\
\hline $6 b(A)$ & 5.5 & 1.90 & 2.5 & 0.90 \\
\hline $7 a(A)$ & 4.8 & 1.90 & 1.8 & 0.90 \\
\hline $7 b(C)$ & 4.6 & 1.55 & 1.9 & 0.85 \\
\hline $8 a(A)$ & 6.1 & 1.65 & 2.0 & 0.85 \\
\hline $8 b(A)$ & 5.8 & 2.30 & 2.2 & 0.90 \\
\hline \multicolumn{5}{|c|}{$\begin{array}{l}\text { The length and diameter of the lateral nasal artery (LNA) and the mean length } \\
\text { and mean diameter of its perforators in each cadaveric specimen are shown. } \\
\text { The letters in parentheses represent the course of the facial artery according to } \\
\text { Nakajima's classification [14], which is presented in Fig. } 2 \text {. }\end{array}$} \\
\hline
\end{tabular}

rators to the main vessel, which can result in a high percentage of false positives, and considering the constancy of this anatomic feature, we decided not to use a Doppler probe.

After the first excision on the nasal labial groove up to the subcutaneous tissue, we performed gentle spreading to show the LNA perforators. The spreading was parallel to the perforator course without approaching too close to the vessel wall in order to reduce the risk of spasm.

When performing a propeller flap, we chose the closest perforator vessel to the defect, whereas we included as many perforators as possible when using a V-Y flap. Once the perforators were selected, they were gently freed from fibrous attachments to the levator labii superioris and levator labii superioris alaeque nasi muscles, and the flap was subsequently islanded on the perforators that were isolated.

The perforator was cuffed with a small portion of the surrounding fatty tissue to protect the vessel from twisting, stretching, and spasm. We incised the caudal border of the flap while keeping the cranial border intact if perforator absence or injury made it necessary to perform a pedicled flap.

Once the perforating artery and vein were identified, the skin was incised circumferentially. The cutaneous nerves were spared

\section{Fig. 3. Distribution of perforators}

The red circle indicates the area with the highest probability of finding perforators. This area corresponds to the upper third of the nasolabial fold lateral to the limit of the ala nasi. The bars represent the cumulative number of facial artery perforators that were found in all cadaveric dissections in consecutive $1-\mathrm{cm}$ sections of the lateral nasal artery. This landmark is helpful considering the difficulty of performing an accurate Doppler study of perforators in this area.

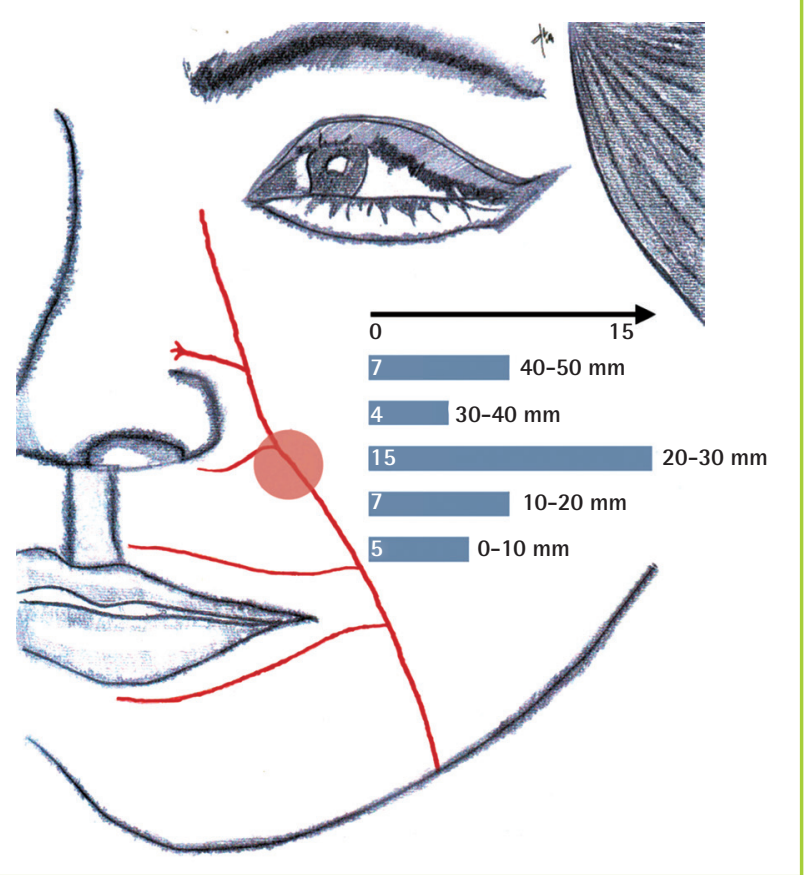


if they did not hinder the movement of the flap. Dissection of the pedicle was performed until tension-free transposition was achieved to cover the defect.

\section{RESULTS}

\section{Cadaveric study}

After determining the general course of the LNA, the measurements described in the Methods section were analyzed (Table 1). The mean total lengths of the LNA and of its perforators were $49.38 \mathrm{~mm}$ (range, 40-61 mm) and $16.6 \mathrm{~mm}$ (range, 13-23 $\mathrm{mm}$ ), respectively. The mean diameters of the LNA and of its perforators were $2.08 \mathrm{~mm}$ (range, $1.7-2.5 \mathrm{~mm}$ ) and $0.91 \mathrm{~mm}$ (range, $0.65-1.25 \mathrm{~mm}$ ).

The distribution of the perforators over the course of the LNA is presented in Fig. 3. The number of perforators varied on each side of the face, so their distribution in each centimeter of the length of the LNA was assessed. The majority of LNA perforators originated between 20 and $30 \mathrm{~mm}$ along the length of the LNA, corresponding to an area of approximately $1 \mathrm{~cm}^{2}$ in the upper third of the nasolabial fold lateral to the limit of the ala nasi, before the LNA gives off the inferior ala nasi artery branch [14]. Based on our findings, we mapped the face to indicate areas with a higher probability of finding perforators (Fig. 3).

\section{Clinical cases}

The clinical cases are summarized in Table 2. No infection, hematoma, or complete flap necrosis was observed after the procedure. One patient suffered from venous congestion, but the wound healed well with conservative treatment during the follow-up period. The cutaneous nerves were maintained in all of the V-Y flaps because they did not hinder the movement of the

\section{Table 2. Demographic data regarding the patients and details of the reconstruction procedures (clinical data)}

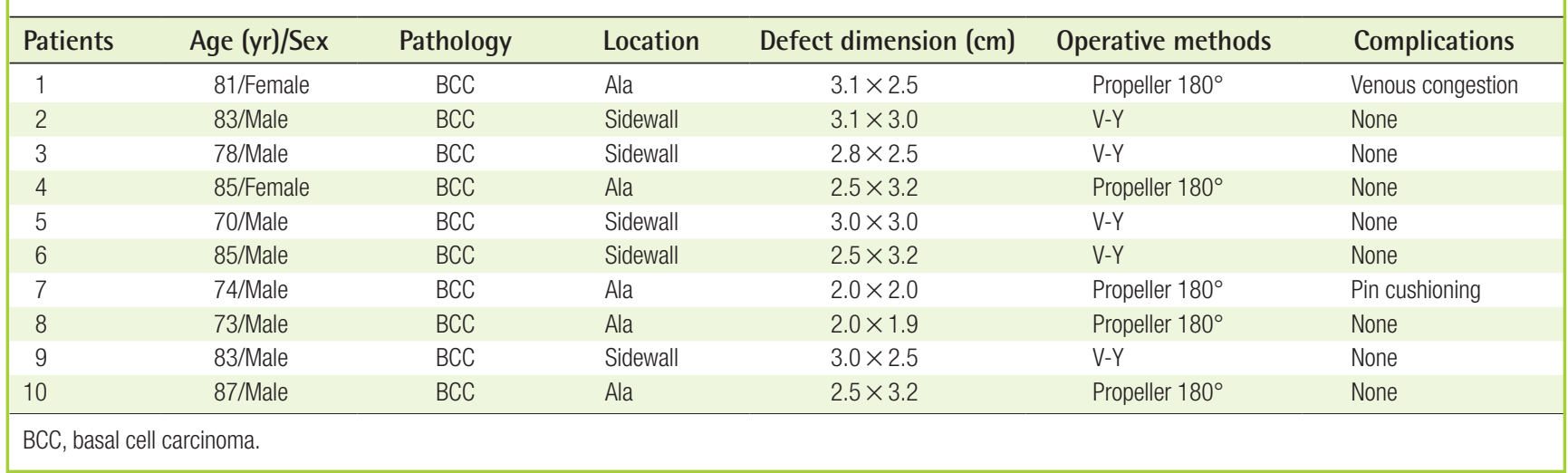

\section{Fig. 4. Case 1}

A 75-year-old woman with basal cell carcinoma. (A) The excision and flap design area were marked. (B) Tumor excision and reconstruction with a $180^{\circ}$ propeller flap after the individuation of the lateral nasal artery perforator. (C) Frontal view of the results six months after the procedure.
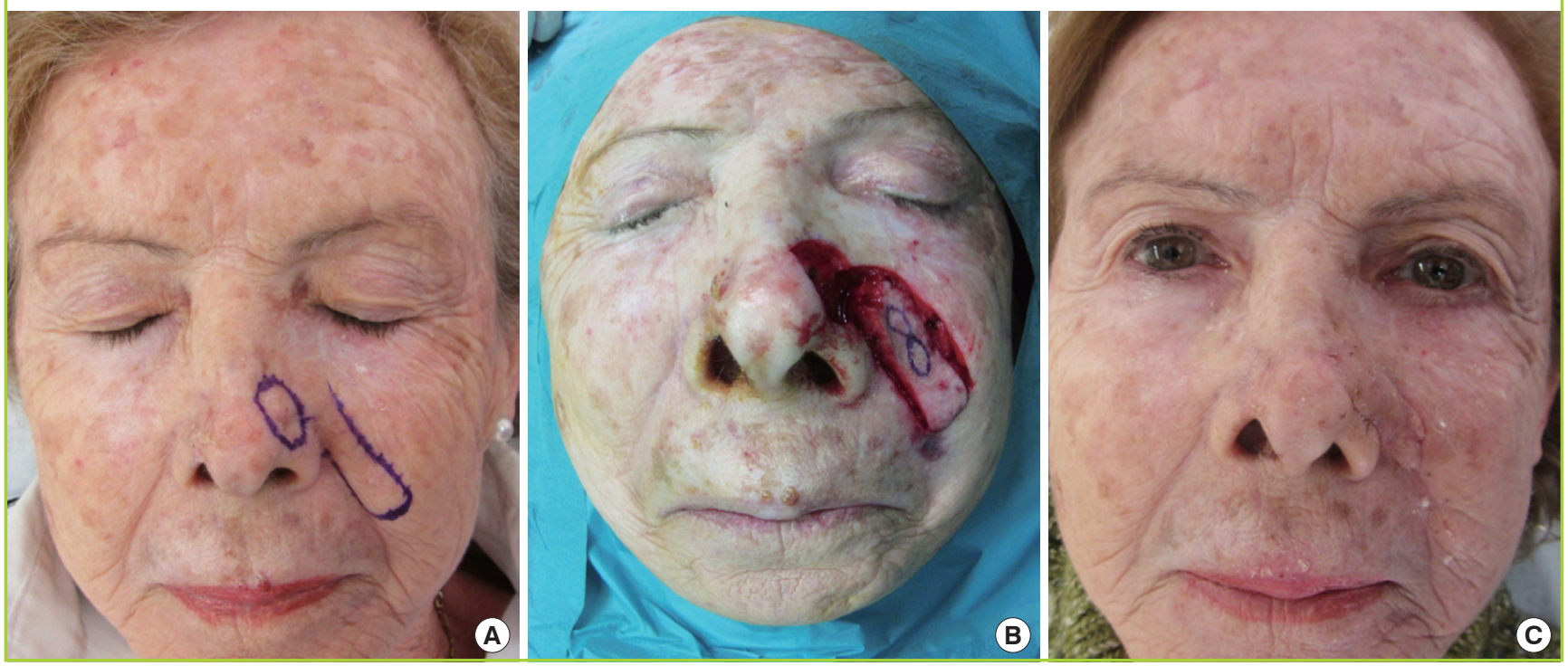
flap, whereas they were spared in two out of the five propeller flaps due to the impossibility of achieving tension-free transposition.
Case 1

An 81-year-old woman underwent excision of a BCC in the left ala nasi. Following resection of the cancer, a perforator from the LNA was used to reconstruct the defect. A $180^{\circ}$ rotation island flap $2 \mathrm{~cm}$ in width and $5 \mathrm{~cm}$ in length was designed. The aes-

\section{Fig. 5. Case 2}

A 78-year-old man with basal cell carcinoma. (A) The excision and flap design area were marked. (B) Tumor excision and reconstruction with a $\mathrm{V}$-Y perforator flap after the individuation of the lateral nasal artery perforator. (C) Frontal view of the results six months after the procedure.
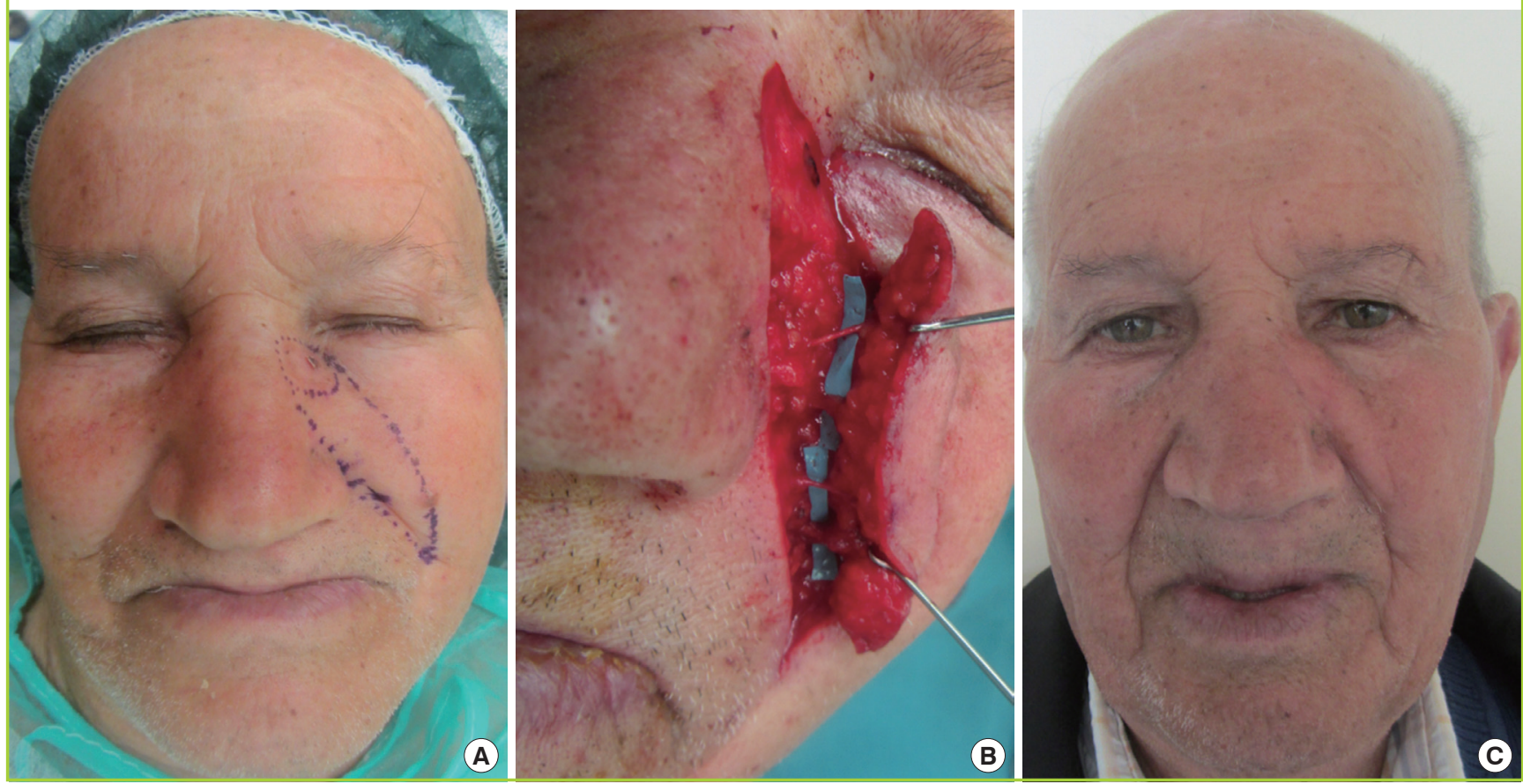

\section{Fig. 6. Case 3}

A 70-year-old man with basal cell carcinoma. (A) The excision and flap design area were marked. (B) Tumor excision and reconstruction with a $\mathrm{V}-\mathrm{Y}$ perforator flap after the individuation and isolation of the lateral nasal artery perforator. (C) Frontal view of the results four months after the procedure.
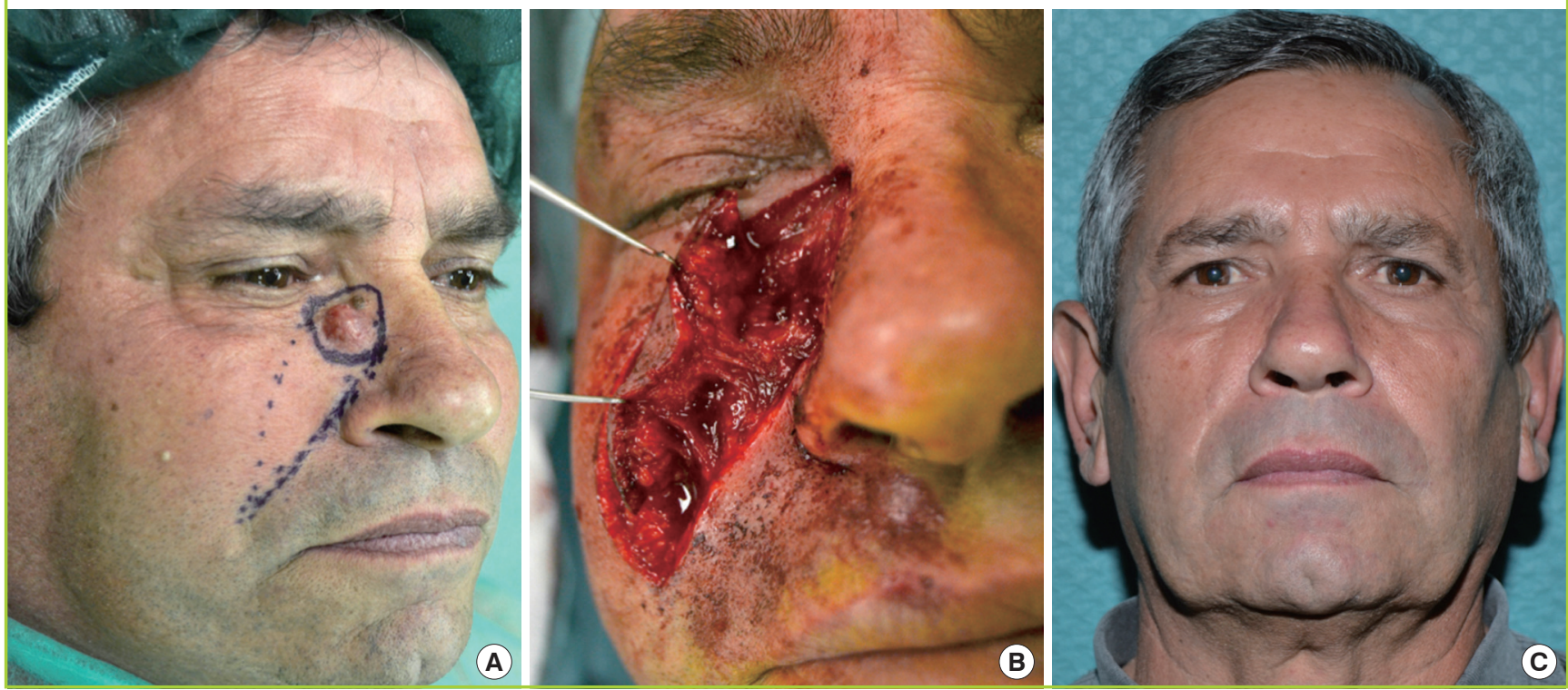
thetic unit was restored. The location of the perforator corresponded to our cadaveric study. No complications were noted (Fig. 4).

\section{Case 2}

An 83-year-old man underwent excision of a BCC in the left nasal sidewall. The defect was covered with an LNA V-Y perforator flap. Two arteries and two venous perforators were included in this flap. The cranial part of the flap was thinned to the level of the subdermal plexus to improve the aesthetic restoration of the nasal sidewall unit (Fig. 5). The location of the perforators corresponded to that identified in our cadaveric study.

\section{Case 3}

A 70-year-old man underwent excision of a BCC in the right nasal sidewall. The defect was covered with an LNA V-Y perforator flap. Two perforators were included in this flap (Fig. 6). The location of the perforators corresponded to that identified in our cadaveric study.

\section{DISCUSSION}

Previous studies have investigated facial artery perforators, but have reported inconsistent results regarding LNA perforators $[3,10,11]$. A number of authors have used LNA perforators for ala nasi and nasal sidewall reconstruction [5-9]. However, the literature contains little information concerning the cadaveric dissection of the LNA perforators, and most previously published studies have focused on facial artery perforators.

Hofer et al. [3] and Ng et al. [12] showed that the distribution of perforators near the base of the ala nasi seems to be inconsistent and reported a very low number of perforators in this anatomic area.

However, we found an area lateral to the ala nasi where perforators were consistently present. This was an area of approximately $1 \mathrm{~cm}^{2}$ corresponding to the upper third of the nasolabial fold lateral to the limit of the ala nasi, before the lateral nasal artery gives off the inferior ala nasi artery branch [14] (Fig. 3).

Although other authors [5-9] have used LNA perforator flaps for nasal reconstruction, to our knowledge, no previous studies have described the anatomic landmarks in a way that could provide guidance to surgeons approaching this area. Based on our cadaveric study, we were able to approach this anatomic area with confidence. This was especially important since preoperative Doppler imaging would not have been helpful in finding perforators due to their proximity to the source vessel, which would have resulted in many false positives.

Nasal defects can be reconstructed through many surgical ap- proaches, including the forehead flap [18], the nasolabial flap [19], and various local flaps [20-23]. The nasolabial area is the ideal donor site for scar concealment in the natural nasolabial fold. Therefore, traditional local flaps, such as nasolabial flaps, are good solutions for nasal defect reconstruction, but they require a two-stage procedure. The LNA perforator-based flap allows freedom in flap design, avoiding this uncomfortable drawback, and allows nasal defects to be reconstructed in a one-stage procedure. Moreover, the nasolabial skin can be advanced as a V-Y shaped perforator flap for nasal sidewall reconstruction without tension or distortion, reaching the dorsum nasi with ease.

Compared to a random subcutaneous V-Y advancement flap, when the flap is islanded on the selected perforators, it is advanced toward the defect more easily, thereby allowing the surgeon to avoid distortion of the surrounding anatomic structures and tension on the suture lines, which could eventually lead to distal flap necrosis [24].

The V-Y technique has significant vascular and aesthetic advantages in comparison to the propeller flap design, but a propeller flap should be considered if the perforator vessel is in close proximity to the defect [24]. According to our cadaveric study, the propeller flap design is the best solution for ala nasi defects, due to the proximity of the perforators to the defect (Fig. 3).

While the V-Y perforator flap does not have significant disadvantages, and it has a wider range of advancement compared to the standard subcutaneous V-Y flap, the LNA propeller perforator flap for ala nasi reconstruction has numerous drawbacks compared to the classic interpolated melolabial flap.

The LNA perforator propeller flap has the following advantages: (1) One-stage reconstruction instead of a two-stage reconstruction technique; (2) The possibility of dissecting an innervated flap; (3) Freedom in flap design and shaping, obviating the necessity to adhere to the length-to-width ratio previously considered necessary to ensure viability. However, the LNA perforator propeller flap has the following disadvantages: (1) Difficult dissection due to the small vessel dimensions, even if the intramuscular course is limited; (2) Pin-cushioning deformity is more frequent in these small perforator flaps compared to the classic interpolated melolabial flap, and the subunit reconstruction is less accurate; (3) Venous congestion can easily occur due to twisting of the vessels, even if the perforator is dissected with a small cuff of surrounding fatty tissue.

Ala nasi reconstruction is a challenging surgical procedure due to the peculiar shape of the ala nasi and because it is desirable to achieve symmetry with the contralateral ala nasi.

In young patients without comorbidities, the classic two-stage procedure is optimal in terms of cosmetic results and because it reduces the risk of complications. However, in certain cases, 
such as elderly patients in whom is preferable to avoid multiple surgical procedures due to anesthesia-associated risks, the LNA propeller flap is an excellent one-stage reconstructive procedure, and our experience suggests that this technique can be successfully applied with acceptable cosmetic results.

LNA perforator flaps are reliable and versatile flaps for reconstruction of the ala nasi and the sidewall of the nose. Our cadaveric study allowed us to identify an area in the upper third of the nasolabial groove with a high density of perforators. This allows a more confident approach to this anatomic area, since preoperative Doppler would not be helpful in finding perforators.

\section{REFERENCES}

1. Allen RJ, Treece P. Deep inferior epigastric perforator flap for breast reconstruction. Ann Plast Surg 1994;32:32-8.

2. Koshima I, Soeda S. Inferior epigastric artery skin flaps without rectus abdominis muscle. BrJ Plast Surg 1989;42:645-8.

3. Hofer SO, Posch NA, Smit X. The facial artery perforator flap for reconstruction of perioral defects. Plast Reconstr Surg 2005;115:996-1003.

4. D’Arpa S, Cordova A, Pirrello R, et al. Free style facial artery perforator flap for one stage reconstruction of the nasal ala. J Plast Reconstr Aesthet Surg 2009;62:36-42.

5. Karsidag S, Ozcan A, Sumer O, et al. Single-stage ala nasi reconstruction: lateral nasal artery perforator flap. J Craniofac Surg 2010;21:1887-9.

6. Brunetti B, Tenna S, Aveta A, et al. Angular artery perforator flap for reconstruction of nasal sidewall and medial canthal defects. Plast Reconstr Surg 2012;130:627e-628e.

7. Sohn WI, Choi JY, Seo BF, et al. Reconstruction of nasal ala with nasolabial perforator flap after cancer removal. Head Neck Oncol 2012;4:83.

8. Kim SW, Kim YH, Kim JT. Angular artery perforator-based transposition flap for the reconstruction of midface defect. Int J Dermatol 2012;51:1366-70.

9. Demirseren ME, Afandiyev K, Ceran C. Reconstruction of the perioral and perinasal defects with facial artery perforator flaps. J Plast Reconstr Aesthet Surg 2009;62:1616-20.

10. Kim JT. New nomenclature concept of perforator flap. Br J
Plast Surg 2005;58:431-40.

11. Kannan RY, Mathur BS. Perforator flaps of the facial artery angiosome. J Plast Reconstr Aesthet Surg 2013;66:483-8.

12. Ng ZY, Fogg QA, Shoaib T. Where to find facial artery perforators: a reference point. J Plast Reconstr Aesthet Surg 2010; 63:2046-51.

13. Qassemyar Q, Havet E, Sinna R. Vascular basis of the facial artery perforator flap: analysis of 101 perforator territories. Plast Reconstr Surg 2012;129:421-9.

14. Nakajima H, Imanishi N, Aiso S. Facial artery in the upper lip and nose: anatomy and a clinical application. Plast Reconstr Surg 2002;109:855-61.

15. Loukas M, Hullett J, Louis RG Jr, et al. A detailed observation of variations of the facial artery, with emphasis on the superior labial artery. Surg Radiol Anat 2006;28:316-24.

16. Burget GC, Menick FJ. The subunit principle in nasal reconstruction. Plast Reconstr Surg 1985;76:239-47.

17. Mardini S, Tsai FC, Wei FC. The thigh as a model for free style free flaps. Clin Plast Surg 2003;30:473-80.

18. Menick FJ. Nasal reconstruction with a forehead flap. Clin Plast Surg 2009;36:443-59.

19. Cameron RR, Latham WD, Dowling JA. Reconstructions of the nose and upper lip with nasolabial flaps. Plast Reconstr Surg 1973;52:145-50.

20. Fabrizio T, Savani A, Sanna M, et al. The retroangular flap for nasal reconstruction. Plast Reconstr Surg 1996;97:431-5.

21. Chu EA, Byrne PJ. Local flaps I: bilobed, rhombic, and cervicofacial. Facial Plast Surg Clin North Am 2009;17:349-60.

22. Kwon KH, Lee DG, Koo SH, et al. Usefulness of v-y advancement flap for defects after skin tumor excision. Arch Plast Surg 2012;39:619-25.

23. Tregaskiss A, Allan J, Gore S, et al. Use of the nasal sidewall island inversion flap for single-stage ala nasi reconstruction: a report of 103 consecutive cases. Plast Reconstr Surg 2014; 133:377-85.

24. Brunetti B, Tenna S, Aveta A, et al. Free-style local perforator flaps: versatility of the v-y design to reconstruct soft-tissue defects in the skin cancer population. Plast Reconstr Surg 2013;132:451-60. 